\title{
Coil valve syndrome: a rare complication of percutaneous transhepatic obliteration successfully treated by argon plasma coagulation and double-balloon endoscopy
}

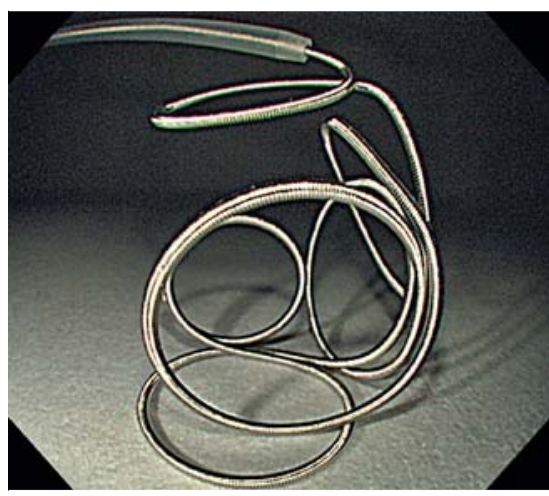

- Fig. 1 Cerecyte coil.

Percutaneous transhepatic obliteration (PTO) is now widely used for prophylactic treatment of gastric varices [1]. A straying coil tip in the stomach is sometimes reported as an adverse event [2,3], but there have been no reports of one reaching the small intestine from the stomach. In this case, the migrated coil tip with food residue was shaped like a ball and passed into the jejunum, causing a phenomenon resembling ball valve syndrome [4].

A 70-year-old woman was admitted with epigastric pain. She had been treated for gastric varices by PTO with coils ( $>$ Fig. 1 ) 4 years earlier. One of these had migrated into the stomach asymptomatically 1 year after PTO ( $>$ Fig. 2 ) and had been carefully monitored. Esophagogastroduodenoscopy on admission revealed the coil extending through the stomach and hooking into the mucosa at the angular portion of the stomach ( $\mathbf{F i g . 3}$ ). Abdominal computed tomography revealed that the coil tip was now in the jejunum (\$Fig.4). Because of the risks of ulceration, perforation, or intussusception, we decided to remove it. Oral double-balloon enteroscopy (DBE) detected the coil tip enveloped by food residue in the jejunum; we carefully grasped it using forceps and pulled it back into the stomach. At first, we failed to cut the coil

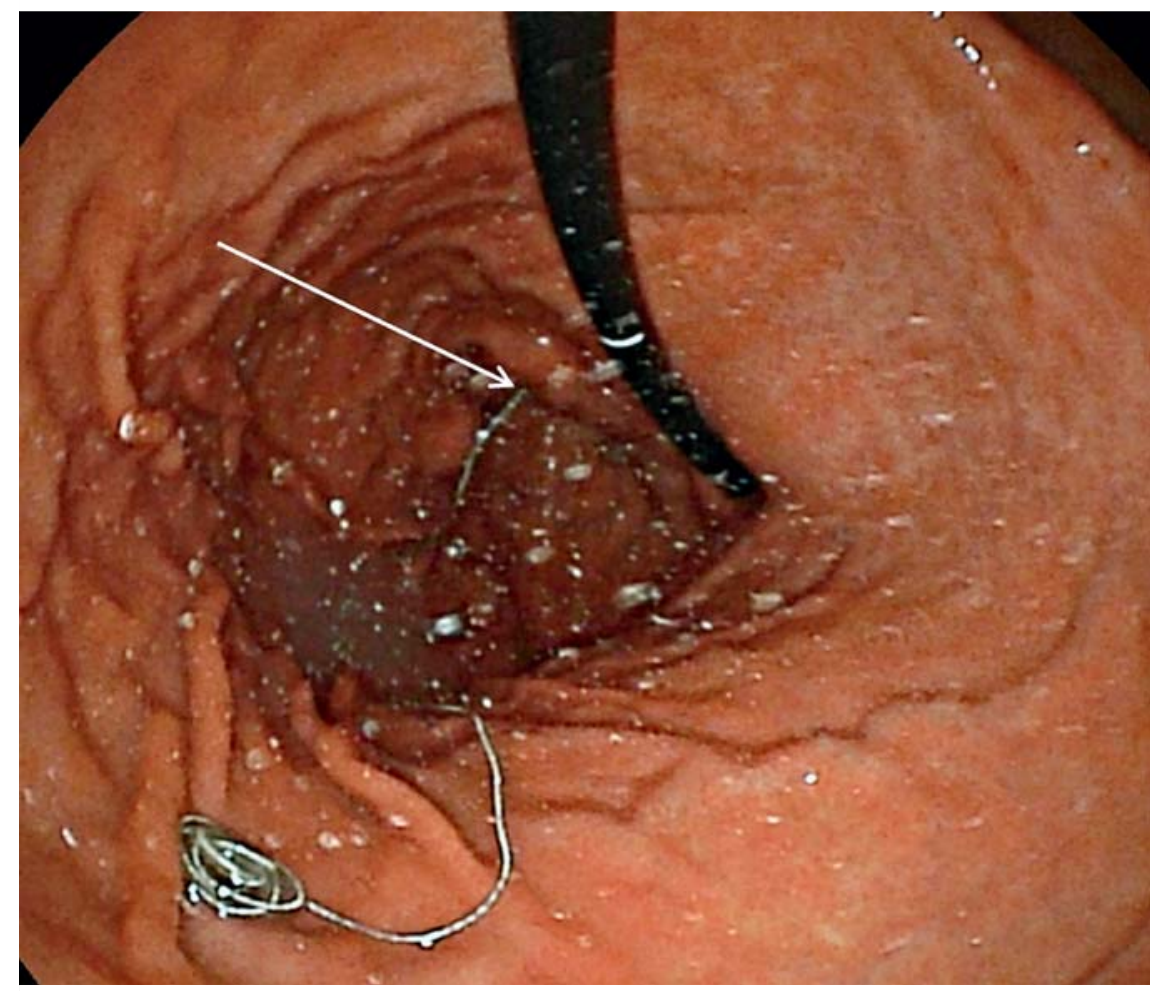

Fig. 2 Endoscopic view of coil used to treat gastric varices, migrating from the fornix of the stomach (arrow).

wire using a scissor-type electrical knife and loop cutter, but we finally succeeded in cutting it using argon plasma coagulation (APC) ( $\triangleright$ Video 1$)$. There were no adverse events during this procedure and the patient's symptoms improved.

The recovered coil was an $82-\mathrm{cm}$ cerecyte coil. It was only possible to cut it using APC because the coil wire had unraveled and lengthened (\$Fig.5). Compared with radiologists, few gastroenterologists know about migrated PTO coils and their characteristics.

This case shows a rare complication of PTO that was successfully treated by APC and DBE. We propose to describe this "coil valve syndrome" as "ball valvelike syndrome due to deviated coil."

Endoscopy_UCTN_Code_CPL_1AK_2AH

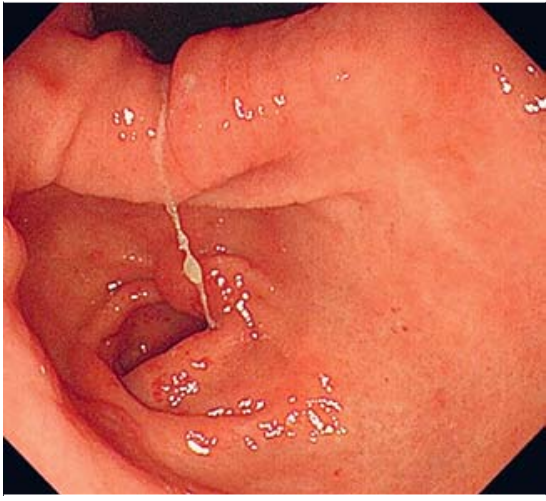

Fig. 3 Endoscopic view of a migrated coil biting into the mucous membrane at the angular portion of the stomach. 


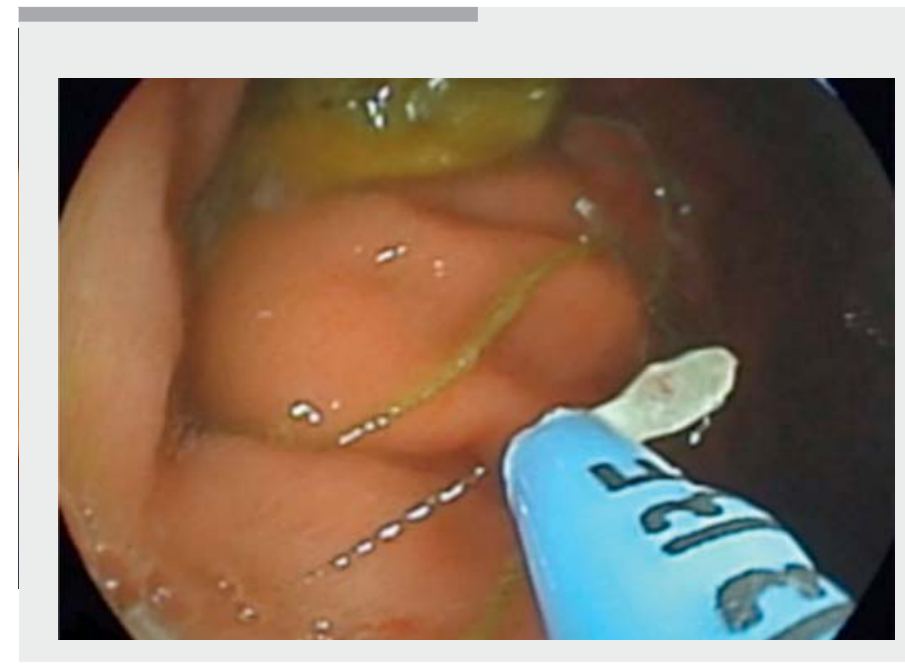

$\square$ Video 1 "Coil valve syndrome": a rare complication of percutaneous transhepatic obliteration for gastric varices that was successfully treated by argon plasma coagulation (APC) and double-balloon endoscopy (DBE).

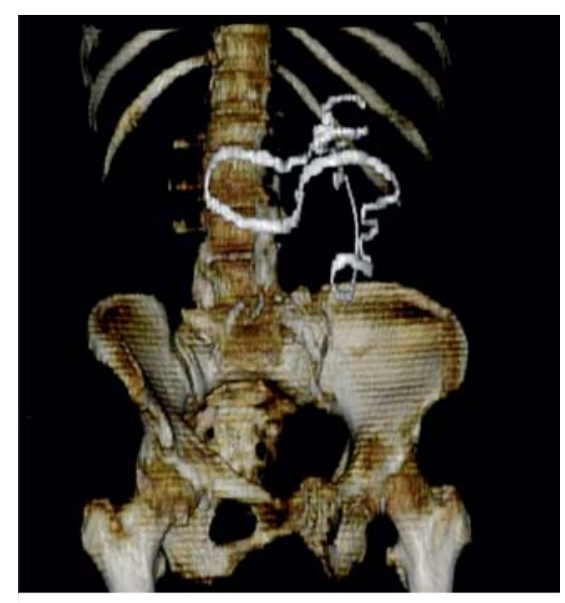

> Fig. 4 Computed tomography (CT) confirmed that the end of the coil was in the jejunum.

Competing interests

None

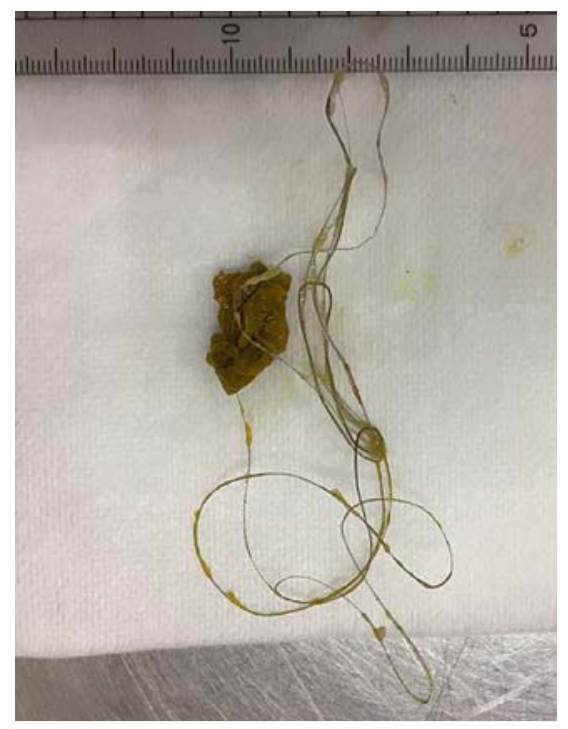

- Fig. 5 The recovered unraveled $82-\mathrm{cm}$ cerecyte coil.

The authors

Koji Nagaike ${ }^{1}$, Shiro Hayashi ${ }^{2}$, Kengo Nagai ${ }^{1}$, Hirokazu Sasakawa ${ }^{1}$, Kiyonori Yuguchi ${ }^{1}$, Yuichi Yoshida ${ }^{1}$, Masafumi Naito ${ }^{1}$

1 Department of Gastroenterology and Hepatology, Suita Municipal Hospital, Osaka, Japan

2 Department of Gastroenterology and Internal Medicine, Hayashi Clinic, Osaka, Japan
Corresponding author

\section{Koji Nagaike, MD}

Department of Gastroenterology and Hepatology, Suita Municipal Hospital, 5-7 Kishibeshinmachi, Osaka 564-8567, Japan

Fax: +81-6-63805825

nagaike.koji@gmail.com

\section{References}

[1] Lunderquist A, Vang J. Transhepatic catheterization and obliteration of the coronary vein in patients with portal hypertension and esophageal varices. N Engl J Med 1974; 291: 646-649

[2] Kawai N, Minamiguchi $\mathrm{H}$, Sato $\mathrm{M}$ et al. Percutaneous transportal outflow-vesseloccluded sclerotherapy for gastric varices unmanageable by balloon-occluded retrograde transvenous obliteration. Hepatol Res 2013; 43: 430-435

[3] Adebajo CO, Waxman I, Chapman C et al. Foiled by coils: upper $\mathrm{Gl}$ bleeding from a rare delayed adverse event of transarterial embolization. Gastrointest Endosc 2017; 85: 1295-1296

[4] Hobbs WH, Cohen SE. Gastroduodenal invagination due to a submucous lipoma of the stomach. Am J Surg 1946; 71: 505-518

\section{Bibliography}

DOI https://doi.org/10.1055/a-0881-2667

Published online: 12.4.2019

Endoscopy 2019; 51: E199-E200

(c) Georg Thieme Verlag KG

Stuttgart · New York

ISSN 0013-726X

\section{CORRECTION}

Koji Nagaike, Shiro Hayashi, Kengo

Nagai et al. Coil valve syndrome:

a rare complication of percutaneous transhepatic obliteration success-

fully treated by argon plasma coagulation and double-balloon endoscopy.

Endoscopy 2019,

doi:10.1055/a-0881-2667

In the above-mentioned article the name of the author Yuichi Yoshida has been corrected.

This was corrected in the online version on May 27, 2019. 